\title{
Cenplasto
}

\section{Produção, busca e compartilhamento de informação no contexto do comércio móvel}

\author{
Maria Aparecida Moura \\ Doutora; Universidade Federal de Minas Gerais, Belo Horizonte, MG, Brasil; \\ mamoura@eci.ufmg.br \\ André Fagundes Faria \\ Mestre; Universidade Federal de Minas Gerais, Belo Horizonte, MG, Brasil; \\ faria.andrefagundes@gmail.com
}

\begin{abstract}
Resumo: Aborda o conceito de consumo. Analisa o desenvolvimento da sociedade de consumo e dos mercados de massa. Identifica características pertencentes ao estudo do comportamento do consumidor. Aborda as modificações no comércio eletrônico causadas por mídias sociais e aplicativos para dispositivos móveis. Apresenta as características do comércio social e do comércio móvel. Discorre sobre as práticas de produção, busca e compartilhamento de informação no contexto do comércio móvel. Evidencia essas práticas informacionais a partir de funcionalidades presentes nos aplicativos Airbnb, Amazon, iFood e Spotify. Constata que, no âmbito do comércio móvel, as práticas informacionais vêm sofrendo modificações que resultam na relação entre consumo informacional, interação mediada e consumo de bens e serviços.
\end{abstract}

Palavras-chave: Comércio social. Comércio móvel. Práticas informacionais. Aplicativos móveis.

\section{Introdução}

O desenvolvimento das tecnologias de informação e comunicação possibilitou o surgimento do comércio eletrônico e, consequentemente, transformou a dinâmica do consumo via web. Entre tais transformações, pode-se destacar o aumento da participação dos consumidores na produção e no compartilhamento de informações relacionadas ao consumo, bem como o emprego de aplicativos de dispositivos móveis projetados para a efetivação das transações comerciais.

Com a constante evolução da web e o surgimento das mídias sociais, a forma original de comércio eletrônico se transformou no que se denomina comércio social - ou social commerce - modalidade que se caracteriza pela 
produção de informação realizada, em grande parte, pelos próprios consumidores e pela formação de comunidades que atuam de modo coletivo em determinadas etapas do processo de consumo, como avaliação de empresas, produtos e serviços e publicação de experiências relacionadas ao consumo. $\mathrm{O}$ catálogo em linha, disponibilizado por organizações com descrições de produtos e serviços, passou a ser acompanhado por uma variedade de informações fornecidas por consumidores empenhados em compartilhar dúvidas e expectativas pré-compra e experiências e avaliações pós-compra.

Nesse contexto, os consumidores têm à sua disposição opiniões de outros consumidores e de sua rede de referência para tomada de decisão. O processo de consumo deixou de ser uma tomada de decisão solitária para ser influenciado por uma ampla audiência disposta a cooperar mutuamente. Segundo Constantinides e Fountain (2008), as preferências e decisões dos consumidores não estão mais baseadas exclusivamente nas informações disponibilizadas pelas mídias de massa tradicionais ou pelo conteúdo de sites corporativos, mas são influenciadas, cada vez mais, pelo conteúdo gerado pelos demais consumidores nas mídias sociais. Percebe-se que, além do consumo de produtos e serviços, o comércio social envolve a produção e o consumo da própria informação.

Considera-se, também, que a popularização da telefonia móvel e o progressivo desenvolvimento de aplicativos comerciais projetados para smartphones modificaram as práticas de consumo. Ao servirem de plataforma para a realização de transações comerciais, os dispositivos móveis, por meio de aplicativos, inauguraram uma nova modalidade de comércio em linha: o comércio móvel ou m-commerce. Esses mesmos dispositivos passaram, então, a disponibilizar informações relacionadas a produtos e serviços, além de oferecer funcionalidades para que os próprios consumidores produzam, busquem e compartilhem informações ligadas ao consumo e efetivem transações comerciais. Em um mesmo aplicativo para dispositivos móveis, portanto, passou-se a conjugar consumo e práticas informacionais. Nesse sentido, pode-se afirmar que o comércio móvel herdou características próprias do comércio social. 


\section{Dimensões teóricas do consumo}

A evolução das práticas sociais de consumo favoreceu o surgimento de novas modalidades de relações comerciais ao longo do tempo. Passou-se das experiências individuais de compra de bens produzidos em larga escala à economia baseada no acesso em rede a produtos e serviços. Diante de uma pluralidade de formas de aquisição e uso de bens e serviços, como podemos, na contemporaneidade, definir o ato de consumir?

Barbosa e Campbell (2006) ressaltam a existência de certa dificuldade em definir o conceito de consumo no âmbito das ciências sociais. Para os autores, em áreas como economia, marketing e ambientalismo, a definição do termo é mais objetiva e está ligada a processos quantificáveis. Já no contexto das ciências sociais, essa definição é mais complexa e envolve diferentes questões, como, por exemplo, a construção de estilos e identidades. Devido a tal complexidade, esses autores afirmam que o consumo é "uma categoria central na definição da sociedade contemporânea" (BARBOSA; CAMPBELL, 2006, p. 26).

Outro modo de compreensão do consumo é apontado por Canclini (1995), que se refere à distinção de classes e grupos sociais. Quanto a esse "aspecto simbólico e estético da racionalidade consumidora" (CANCLINI, 1995, p. 55), Canclini afirma que há uma coerência entre uma classe e os bens que consome, os quais funcionam como elementos de distinção simbólica à medida que existe certa dificuldade de que outros os possuam. $\mathrm{O}$ autor se refere ainda à "racionalidade integrativa e comunicativa" (CANCLINI, 1995, p. 56) do consumo, segundo a qual, por existir um sentido compartilhado dos bens dentro de um mesmo grupo social, o consumo serve como elemento de agregação social em torno de distinção e de significado comuns.

Devido à relevância e ao impacto do consumo na configuração da sociedade, esta passou a ser caracterizada como sociedade de consumo, definida por Baudrillard (1991, p. 81) como a "sociedade da aprendizagem do consumo e de iniciação social ao consumo", o qual ainda relaciona a existência de tal 
sociedade a um "sistema econômico de alta produtividade", capaz de atender às demandas crescentes e cada vez mais diferenciadas da economia de mercado.

Em âmbito global, o início do desenvolvimento dos mercados de massa se deu a partir do final do século XIX. De acordo com Lipovetsky (2007), que divide a história do capitalismo de consumo em três etapas, "O ciclo I da era do consumo de massa começa por volta dos anos 80 do século XIX e termina com a Segunda Guerra Mundial.” (LIPOVETSKY, 2007, p. 23). Segundo o autor, essa foi uma época de aperfeiçoamento industrial, de surgimento de produtos relacionados à marca de seu fabricante, da publicidade e dos "grandes armazéns" que atuavam em nível nacional na América do Norte e na Europa. Lipovetsky (2007) ainda afirma que houve um processo de democratização do acesso aos bens de consumo devido à "[...] nova filosofia comercial [...] de vender uma grande quantidade de produtos com uma reduzida margem de lucro por unidade, em vez de uma pequena quantidade com uma margem significativa." (LIPOVETSKY, 2007, p. 25).

Identifica-se, no pós-guerra, a segunda fase das economias de consumo, que se estende até o fim da década de 1970. De acordo com Lipovetsky (2007), esse segundo período que caracteriza a sociedade de consumo é marcado pela prevalência do individualismo em detrimento de uma identidade coletiva e pela "lógica da quantidade" em que se destacam "[...] os produtos emblemáticos da sociedade de afluência: automóvel, televisão, aparelhos electrodomésticos." (LIPOVETSKY, 2007, p. 28).

Por fim, na terceira fase identificada por Lipovetsky, o consumo deixa de ser motivado pela ostentação e pela necessidade de reconhecimento social e passa a priorizar a satisfação dos sentidos e a experiência íntima. De acordo com o autor, nessa fase, "[...] em que o valor recreativo se sobrepõe ao valor honorífico, [...] o conforto sensitivo à ostentação, [...] [surgem as] novas funções subjetivas do consumo." (LIPOVETSKY, 2007, p. 37-38). Nesse sentido, Lipovetsky (2007) cunha o termo "consumo emocional", que se caracteriza pelas possibilidades de experiências e sensações pessoais que o consumo pode trazer, bem como pelo desejo de individualização perseguido 
pelos sujeitos. Pode-se afirmar que a "fase III" de Lipovetsky corresponde ao que Jeremy Rifkin (2001) identificou por "Era do acesso". Segundo o sociólogo e economista estadunidense, a sociedade de consumo passou a valorizar as experiências proporcionadas pelo acesso a bens e serviços em lugar do valor atribuído à propriedade material.

Com a mudança de foco apontada por Schultz, Tannenbaum e Lauterborn (1993), a partir da década de 1990, iniciaram-se os estudos de comportamento do consumidor. De acordo com Henao e Córdoba López (2007), trata-se de um tipo de estudo que analisa o conjunto de atos que faz com que os indivíduos busquem, comprem, usem, avaliem e se apropriem de produtos e serviços com os quais esperam satisfazer suas diferentes necessidades. Howard e Sheth $\left(1969^{1}\right.$ apud HENAO; CÓRDOBA LÓPEZ, 2007) destacam que as teorias sobre o comportamento do consumidor podem explicar o consumo e as diferenças comportamentais dos consumidores durante o processo de compra.

Henao e Córdoba López (2007) ainda indicam fatores considerados a partir de diferentes disciplinas e que interferem na conduta de consumo dos indivíduos. De acordo com os autores, o contexto social, a família, os grupos de referência, a cultura e as classes sociais são fatores que podem impulsionar, acelerar ou paralisar o ato de consumir, o que requer uma análise interdisciplinar de tal comportamento.

\section{Comércio móvel}

A contínua evolução da web ensejou uma mudança de foco entre os usuários, que passaram a privilegiar a produção de conteúdo em detrimento do uso da tecnologia em si. A possibilidade de participação se converteu em realidade e, desde então, a interação e a colaboração se tornaram características indissociáveis da rede (JESUS; CUNHA, 2012). Quanto à publicação de conteúdo nessa fase, Neubert e Rodrigues (2012) afirmam que “[...] usuários criam e consomem conteúdo simultaneamente em um modelo de comunicação 
de 'muitos para muitos', no qual comportam-se ora como produtores, ora como consumidores de conteúdo.” (NEUBERT; RODRIGUES, 2012, p. 145).

No cenário de democratização da produção de informação, as mídias sociais vêm desenvolvendo importante função no compartilhamento de conteúdo gerado pelos próprios usuários. Por meio delas, os consumidores obtêm e fornecem informações a uma audiência ampliada e com perfil variado.

No contexto do comércio eletrônico, Tang, Gu e Whinston (2012) definem mídias sociais como "[...] fontes de informação on-line criadas, iniciadas, divulgadas e usadas por consumidores, com a intenção de se educarem sobre produtos, marcas e serviços [...]"2 (TANG; GU; WHINSTON, 2012, p. 44, tradução nossa). Por sua vez, Sterne (2011) identifica seis categorias de mídias sociais, dentre as quais cita os fóruns e quadros de mensagens e as redes sociais - quanto a essa última categoria, entende-se que o autor se refere às ferramentas de redes sociais, plataformas capazes de propiciar a formação de redes sociais on-line, com usuários organizados em torno de interesses comuns.

A produção de informação por consumidores gerou consequência no modelo tradicional de comércio eletrônico e o transformou em comércio social, modalidade caracterizada pela atuação de comunidades que utilizam as mídias sociais para divulgação de informações relacionadas ao consumo, avaliando tanto os bens e serviços quanto as organizações que os comercializam. Nesse contexto, as mídias sociais podem ser utilizadas como plataforma direta para a realização de transações comerciais.

Baseados em uma revisão de literatura sobre o social commerce, Zhang e Benyoucef (2016) identificam dois tipos principais de comércio social: um, em que às ferramentas de redes sociais on-line são incorporadas características comerciais que permitem compra, venda e publicidade; e outro, em que sites pertencentes ao modelo tradicional de comércio eletrônico agregam ferramentas de redes sociais on-line a fim de garantir a interação entre consumidores, bem como entre esses e vendedores.

A dinâmica de produção e compartilhamento de informações também encontra suporte nos aplicativos projetados para smartphones. Quando 
desenvolvidos diretamente para o comércio eletrônico, esses aplicativos permitem, por exemplo, que consumidores avaliem o bem adquirido e expressem sua experiência de consumo. A comunidade de usuários do aplicativo pode acessar o conteúdo gerado pelos consumidores e, a partir de então, orientar sua decisão de compra.

Rashedul Islam, Rofiqul Islam e Mazumder (2010) definem aplicativos móveis como um tipo de software projetado para dispositivos móveis, como smartphones e tablets, e que permitem ao usuário realizar tarefas específicas. Segundo esses autores, os primeiros aplicativos surgiram para o desempenho de tarefas básicas como alarmes de relógios e calculadoras. Entretanto, a evolução dos sistemas permitiu que o desenvolvimento dos aplicativos passasse a ser baseado na internet e, consequentemente, surgiram softwares capazes de realizar atividades mais complexas, como a efetivação de transações comerciais.

Os aplicativos projetados para o comércio eletrônico contribuíram para o surgimento do comércio móvel ou mobile commerce (m-commerce), que consiste na efetivação de transações comerciais por meio de dispositivos móveis. Tiwari e Buse (2007 ${ }^{3}$ apud CHAN; CHONG, 2013) definem $\mathrm{m}$ commerce como algum tipo de transação que envolva a transferência de propriedade ou direitos de uso de produtos e serviços, e que tal transação é iniciada e/ou completada por meio da web e com o suporte de dispositivos móveis.

Ao utilizar aplicativos para a compra de produtos e contratação de serviços, consumidores também contam com as opiniões de seus pares para obter um conhecimento mais amplo sobre o bem que pretendem adquirir. Por oferecer funcionalidades que permitem a avaliação e a postagem de comentários sobre a percepção resultante do consumo, tais aplicativos são percebidos como fontes de informação por consumidores potenciais que desejam conhecer a opinião de outros consumidores em relação à experiência com o produto ou serviço adquirido. 


\section{Práticas informacionais no contexto do $m$-commerce: produção, busca compartilhamento de informação}

Em contextos relacionados ao consumo, percebe-se que indivíduos recorrem a fontes informais de informação a fim de ampliar seu conhecimento sobre bens e serviços que pretendem adquirir e, consequentemente, reduzir o grau de incerteza e insegurança próprio dessa fase.

Ao tratar das etapas do processo de tomada de decisão relativo ao consumo, Solomon (2011, p. 336) afirma que tal processo é iniciado pelo "reconhecimento de um problema". Esse reconhecimento surge do conflito entre aquilo que um indivíduo possui em determinado momento e o que ele passa a desejar. Identificado esse desejo, pode-se afirmar que o indivíduo se converte, então, em potencial consumidor e dá início à busca de informações sobre o bem que deseja, ação que pode ser considerada uma pesquisa pré-compra, em contraposição à pesquisa contínua (BLOCH; SHERRELL; RIDGWAY, 1986). A pesquisa pré-compra é definida por Kelly (1968, p. $273^{4}$ apud BLOCH; SHERRELL; RIDGWAY, 1986, p. 120) como "[...] atividades de busca e processamento de informação com as quais o indivíduo se envolve a fim de facilitar a tomada de decisão em relação a algum objetivo no mercado."5, ou seja, trata-se de uma pesquisa que, necessariamente, antecede a intenção de consumo imediato. Já a pesquisa contínua é definida como "[...] atividades de pesquisa que independem de necessidades ou decisões específicas de compra." (BLOCH; SHERRELL; RIDGWAY, 1986, p. 120), não motivada por intenções súbitas de consumo.

Bloch, Sherrell e Ridgway (1986) propuseram uma estrutura conceitual relativa à busca de informação pelo consumidor. De acordo com tal estrutura, enquanto a pesquisa pré-compra tem como um de seus determinantes o envolvimento pontual com a compra, é motivada pela intenção de otimizar a tomada de decisão de consumo e tem como um de seus resultados o maior conhecimento do bem a ser adquirido; a pesquisa contínua, por sua vez, tem como um de seus determinantes o envolvimento permanente com o produto, é 
motivada pelo desejo de ampliar o conhecimento sobre o mesmo, ainda que seja para um possível uso futuro, e apresenta como um de seus resultados o aumento da influência pessoal do consumidor em sua relação com seus pares.

O tipo de pesquisa realizado também sofre diferenciação, de acordo com Solomon (2011), há pesquisas deliberadas e pesquisas acidentais. Enquanto estas são marcadas pela passividade na aquisição de informações e ocorrem devido à exposição do consumidor a anúncios publicitários, por exemplo, aquelas são caracterizadas pelo direcionamento e foco na obtenção de informações relevantes sobre produtos e serviços.

Moon (2004) propôs um modelo a fim de compreender os motivos que levam os consumidores a elegerem a web como fonte de informação sobre produtos em detrimento de canais tradicionais. Segundo esse modelo, há três fatores que influenciam a busca por informações relacionadas ao consumo na internet: perfis dos consumidores, objetivos da busca de informações e características das páginas web. Também são apontadas variáveis que interferem em cada uma das categorias propostas: os perfis dos consumidores são condicionados pelo seu nível de conhecimento, habilidade em utilizar os serviços da internet, disposição em assimilar as funcionalidades da internet, estilo de vida e características demográficas; os objetivos da busca são condicionados pelo tipo de pesquisa executada - busca pré-compra ou busca contínua; por sua vez, as características das páginas web são influenciadas pela quantidade de informação disponibilizada, design da página, velocidade de acesso e transmissão de informações, mecanismos de busca amigáveis e frequência de atualização de conteúdo.

Quanto às pesquisas on-line, Solomon (2011, p. 338) destaca a atuação dos "infocompradores", consumidores que "quase automaticamente" recorrem à web a fim de buscar informações antes de efetivarem a compra de bens ou a contratação de serviços. Como exemplo, o autor cita uma enquete realizada nos Estados Unidos na qual foi constatado que $90 \%$ dos respondentes que se enquadram na definição de "infocompradores" afirmaram que "[...] confiam mais no que aprendem on-line do que a partir de qualquer outra fonte (incluindo 
vendedores)." (SOLOMON, 2011, p. 338). Solomon (2011, p. 353) ainda aponta a figura do cibermediador, "[...] intermediário que auxilia a filtrar e organizar informações de mercado on-line de forma que os clientes possam identificar e avaliar alternativas de maneira mais eficiente".

Nesse âmbito, pode-se afirmar que as organizações também empregam um comportamento de busca de informação. Tal fato se evidencia, por exemplo, pelo monitoramento de mídias sociais, realizado pelas organizações a fim de captar as preferências e o grau de satisfação de consumidores. Tais informações podem servir de insumo para o aperfeiçoamento de produtos e serviços, bem como para traçar estratégias publicitárias e de marketing personalizado.

Por sua vez, a produção de informação é um aspecto capaz de gerar impactos consideráveis sobre a condução dos negócios das organizações. O conteúdo gerado por consumidores baseado em experiências de consumo pode interferir nas tomadas de decisões de seus pares no momento da aquisição de bens. Considerada por Blackwell, Miniard e Engel (2005) como uma das etapas do processo de tomada de decisão de consumidores, a avaliação pós-consumo disponibilizada em rede pode influenciar as decisões de compra dos sujeitos, seja essa atividade realizada on-line ou off-line. Concomitantemente, por meio das atividades de comunicação, as organizações também participam do processo de produção de informação no contexto do comércio eletrônico.

Essa pluralidade de produtores de conteúdo pode ser relacionada às três dimensões da comunicação organizacional identificadas por Baldissera (2009): "organização comunicada", "organização comunicante" e "organização falada".

Baldissera (2009) afirma que há certa tendência em se reduzir a comunicação organizacional aos processos comunicacionais oficiais e planejados, os quais constituem o conceito de "organização comunicada". Para o autor, a organização comunicada compreende os "[...] processos formais e [...] disciplinadores da fala autorizada; aquilo que a organização seleciona de sua identidade [...]" (BALDISSERA, 2009, p. 118) a fim de transmiti-lo ao público.

Quanto ao processo de comunicação organizacional, que se dá por meio da interação com outros atores sociais, Baldissera (2009, p. 118) afirma que tal 
tipo de comunicação origina a "organização comunicante". Nesse nível, pode-se afirmar que existe um processo discursivo que pode ser ora harmônico, ora conflituoso. No contexto do comércio eletrônico, entende-se que o processo de produção do discurso será harmônico quando as informações disponibilizadas pelos consumidores estiverem de acordo com as informações que a organização transmite. Por outro lado, ao interagir com a organização, disponibilizando informações que carregam o potencial de prejudicar a imagem da mesma, os consumidores podem iniciar uma relação discursiva conflituosa, já que o conteúdo negativo produzido tenderá a desconstruir a imagem organizacional e exigirá que as organizações realizem ações para neutralizar críticas.

O terceiro e último conceito apresentado por Baldissera (2009) em relação à noção de comunicação organizacional é o de "organização falada". Para o autor, esse aspecto relaciona-se aos "[...] processos de comunicação informal indiretos; aqueles que se realizam fora do âmbito organizacional e que dizem respeito à organização - algo como organização falada." (BALDISSERA, 2009, p. 119, grifo do autor). Como exemplo de tais processos, podem ser citadas as conversações realizadas entre grupos de amigos, bem como entre grupos de consumidores no contexto das redes sociais on-line, conversações essas surgidas a partir da experiência de consumo de produtos e serviços de determinada marca. A avaliação desse tipo de experiência leva à percepção das marcas e organizações vinculadas aos bens consumidos, momento em que fica evidente o grau de satisfação - ou insatisfação - dos consumidores.

O compartilhamento de informação entre consumidores apoia a formação dos sujeitos para o consumo e a propagação de informações relativas às funcionalidades e qualidades de bens adquiridos que não são, necessariamente, encontradas nos catálogos oferecidos por comerciantes. Mills, Knezek e Khaddage (2014) afirmam que o acesso a dispositivos móveis, a busca e o compartilhamento de informação são os principais componentes facilitadores da aprendizagem informal. 
O conjunto de recomendações, críticas e avaliações feito por usuários/consumidores sustenta a propaganda boca-a-boca, ou seja, um tipo de marketing feito pelos próprios consumidores a partir de experiências de consumo. Ao tratar dessa prática no contexto do comércio eletrônico, Hyrynsalmi e outros (2015) afirmam que, no e-commerce, particularmente, existe certa dificuldade em avaliar previamente produtos ou serviços e os benefícios e valores que eles podem possuir. Por isso, potenciais consumidores tendem a confiar em fontes de informação independentes, tais como outros consumidores que já experimentaram o produto. Ainda em relação à propaganda feita entre os próprios consumidores, Duan, Gu e Whinston (2008) destacam que tal prática disponibiliza uma fonte de informação alternativa para os consumidores. Tsao (2013) afirma que o compartilhamento dessas informações interfere diretamente na preferência dos consumidores. Citando uma série de outros estudos, o autor destaca que a recomendação de produtos por meio de informações baseadas na experiência de consumo pode reduzir a sobrecarga de informações disponíveis e simplificar a busca por informação para o consumidor, melhorar a qualidade da tomada de decisão, aumentar o grau de confiança nas decisões relativas ao consumo e influenciar o comportamento do consumidor e suas intenções de compra.

\section{Metodologia}

A fim de compreender as características dos processos de produção, busca e compartilhamento de informação no contexto do comércio móvel, foram definidos quatro aplicativos de comércio eletrônico como objetos de análise do aspecto informacional inerente às relações comerciais no contexto do $\mathrm{m}$ commerce. Os aplicativos selecionados, baseados no sistema operacional Android, foram: Airbnb, Amazon, iFood e Spotify. A escolha levou em conta algumas funcionalidades que os mesmos oferecem, como canais de interação entre os usuários, manutenção da oferta de serviço com base nas atividades dos usuários e estímulo à publicação de conteúdo pelos mesmos. 
Inicialmente, procedeu-se à análise individual das funcionalidades de cada aplicativo relacionadas a tais processos. Nesse sentido, fez-se um exame dos mecanismos que permitem a produção de conteúdo no contexto dos aplicativos, seja por parte dos usuários/consumidores, seja por parte das próprias organizações. Além disso, foram consideradas as diretrizes relacionadas à produção de conteúdo apresentadas por cada organização.

Em seguida, foram analisadas as ferramentas de busca de informação dos aplicativos, a fim de compreender a dinâmica de recuperação de informação e identificar funcionalidades que favorecem a recuperação de informações personalizadas.

Por fim, foram observadas as funções relacionadas ao compartilhamento de informação, observando como a difusão de conteúdo no contexto da rede de usuários/consumidores é estimulada.

Salienta-se que, em cada caso, os aplicativos foram comparados em função das funcionalidades apresentadas e das características que as mesmas contêm.

\section{Produção, busca e compartilhamento de informação no contexto de aplicativos móveis}

A seguir, serão analisadas as funcionalidades relativas aos processos de produção, busca e compartilhamento de informação no contexto dos aplicativos, a fim de destacar o modo como tais funcionalidades configuram essas práticas informacionais.

\subsection{Produção de informação}

A Figura 1 exibe telas que exemplificam os processos de produção de informação nos aplicativos analisados. 
Figura 1 - Produção de informação no contexto dos aplicativos Airbnb, Amazon e iFood

(1)

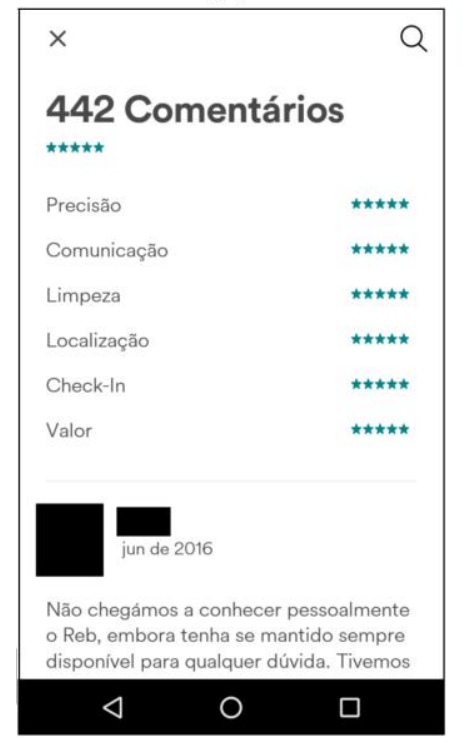

(2)

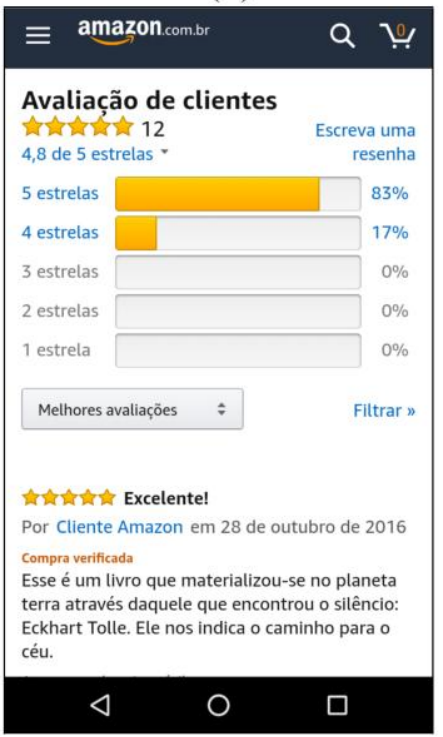

(3)

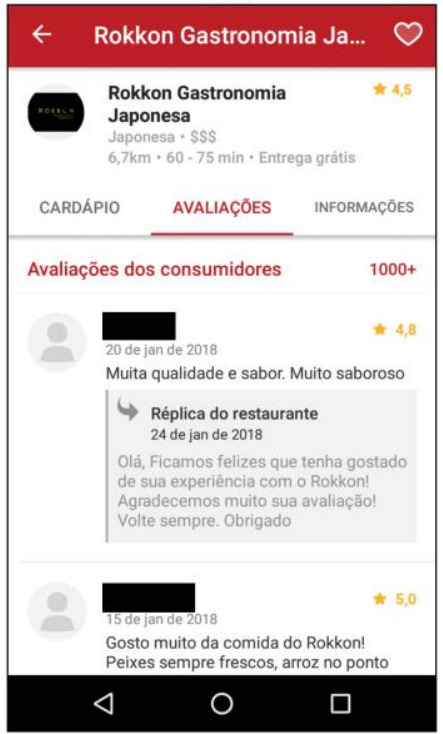

Fonte: Aplicativos Airbnb, Amazon e iFood, adaptado pelos autores. Versões sistema operacional Android.

Legenda: (1) Airbnb; (2) Amazon; (3) iFood.

No aplicativo Airbnb, a produção de informação ocorre por meio de classificações - para hospedagens, apenas - e comentários dos usuários à medida que estes utilizam os serviços oferecidos por outros membros da comunidade.

De acordo com as regras que regulamentam a publicação de comentários no aplicativo, o conteúdo deverá se restringir às experiências reais dos contratantes de serviços, sendo proibida a publicação de spam e de conteúdo relacionado a atividades comerciais, ilegais, discriminatórias, obscenas, difamatórias, dentre outras. Comentários que fujam ao tema proposto no contexto do aplicativo poderão ser removidos e, dependendo do caso, os perfis dos usuários responsáveis por violar as regras de produção de conteúdo poderão ser excluídos pela organização Airbnb. Ressalta-se que comentários podem ser passíveis de denúncia por todos os membros da comunidade. Para tal, ao fim de cada avaliação textual, é disponibilizado o link "Denunciar", por meio do qual usuários que perceberem algum tipo de violação da Política de Conteúdo possam denunciar, anonimamente, o comentário como inapropriado. 
No aplicativo Amazon, a produção de informação também ocorre por meio de classificações e comentários sobre os produtos. Entretanto, a publicação dessas informações não se restringe aos produtos adquiridos pelo consumidor: basta que o mesmo possua um perfil ativo e tenha efetivado uma compra de valor mínimo pré-estabelecido na loja on-line da organização para que possa avaliar e escrever comentários sobre qualquer produto disponível.

Cada comentário possui associadas três opções de validação dos mesmos. Duas dessas opções, "Útil" e "Não é útil", permitem que os demais membros da comunidade indiquem se determinado comentário publicado teve utilidade ou não para a decisão de adquirir o produto, por exemplo. A terceira opção de validação, "Informar", é oferecida para indicar à organização Amazon se o comentário possui conteúdo impróprio e, portanto, deveria ser removido do quadro de avaliações.

O site da Amazon (2017) apresenta a seção "Diretrizes da comunidade", a qual aborda, entre outras, questões relacionadas à proibição de publicação de conteúdos ilegais, comerciais, impróprios ou que não estejam diretamente relacionados à experiência de compra do usuário. Pode-se afirmar que as regras para as "avaliações de clientes" estão explicitamente definidas em uma política de produção de informação.

Por sua vez, a produção de informação no aplicativo iFood também ocorre por meio das classificações por estrelas e das avaliações textuais feitas por usuários/consumidores na seção de cada estabelecimento. Assim, ao selecionar alguma opção de restaurante, por exemplo, o usuário terá acesso à aba "Avaliações", na qual constam as classificações, que variam de uma a cinco estrelas, e os comentários sobre o estabelecimento e os pratos consumidos.

As avaliações feitas pelos consumidores podem receber a réplica do estabelecimento, se posicionando diante de críticas ou elogios, por exemplo. Percebe-se, nessa funcionalidade, a possibilidade dada aos estabelecimentos de reduzirem o impacto dos comentários negativos ou endossarem os comentários de conteúdo positivo, preservando a imagem da organização. 
Embora a organização estabeleça termos e condições de uso dos serviços prestados, nota-se que o documento que trata de tal assunto não aborda regras de produção de conteúdo por parte dos usuários/consumidores. Não há normas claras que restrinjam a publicação de informações ilegais ou que possam violar os direitos de outros membros da comunidade de usuários.

Ao contrário dos demais aplicativos para smartphones analisados neste estudo, o aplicativo Spotify não possui funcionalidades que permitem, no ambiente do próprio aplicativo, a produção de informação por parte dos usuários. A esse respeito, entende-se que a interação por meio da produção de conteúdo entre os membros da comunidade de usuários no aplicativo é bastante reduzida.

A fim de realizar uma leitura global dos processos relacionados à produção de informação no m-commerce, fez-se uma comparação (Quadro 1) dos aplicativos analisados considerando as funcionalidades relacionadas à produção de conteúdo.

Quadro 1 - Características/funcionalidades relativas à produção de informação no contexto dos aplicativos

\begin{tabular}{|c|l|l|l|l|}
\hline \multirow{2}{*}{ Característica/funcionalidade } & \multicolumn{3}{|c|}{ Aplicativos } \\
\hline & Airbnb & Amazon & iFood & Spotify \\
\hline Política de conteúdo & & & & \\
\hline $\begin{array}{c}\text { Regras de produção de } \\
\text { comentários }\end{array}$ & & & & \\
\hline Avaliações textuais & & & & \\
\hline $\begin{array}{c}\text { Réplicas de } \\
\text { organizações/estabelecimentos }\end{array}$ & & & & \\
\hline $\begin{array}{c}\text { Classificações de produtos ou } \\
\text { serviços (atribuição de } \\
\text { estrelas, por exemplo) }\end{array}$ & & & & \\
\hline $\begin{array}{c}\text { Validação de comentários por } \\
\text { membros da comunidade }\end{array}$ & & & & \\
\hline
\end{tabular}

Fonte: Elaborado pelos autores.

A valorização da dimensão de comércio social pode ser percebida pela presença de funcionalidades que facilitam a produção de informação por parte 
dos usuários. A Airbnb e Amazon, ao habilitarem a opção de validar comentários feitos por outros membros da comunidade, ampliam o alcance da produção de conteúdo e, ao mesmo tempo, permitem que os próprios usuários sejam responsáveis pela filtragem de informações, indicando a relevância das mesmas.

Esses aplicativos foram os únicos a apresentarem regras claras para a produção de conteúdo pela comunidade de usuários.

Considera-se que a definição de uma política de conteúdo voltada aos ambientes digitais nos quais a organização se faz presente revela a importância da participação dos usuários na manutenção dos modelos de negócio analisados.

\subsection{Busca de informação}

As ferramentas de pesquisa dos aplicativos devem ser acessíveis e capazes de reduzir o esforço cognitivo empregado por usuários nos processos de busca de informação, já que, em geral, as mesmas são agrupadas sob rótulos devido à limitação de espaço das telas de dispositivos móveis.

A seguir, serão analisados os sistemas de busca (Figura 2) presentes em cada aplicativo, explicitando as particularidades dos mesmos a fim de realizar uma análise comparativa entre os sistemas. 
Figura 2 - Ferramentas de busca dos aplicativos Airbnb, Amazon, iFood e Spotify

(1)

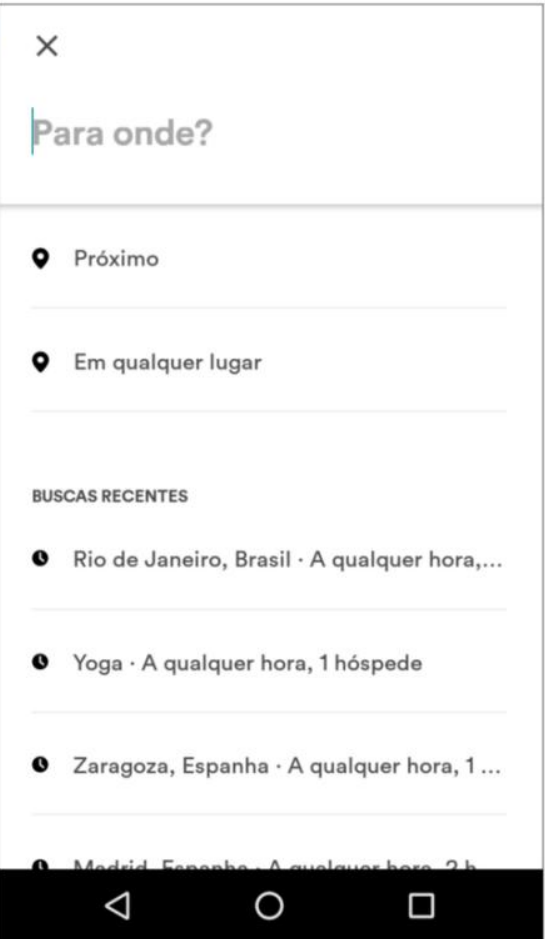

(3)

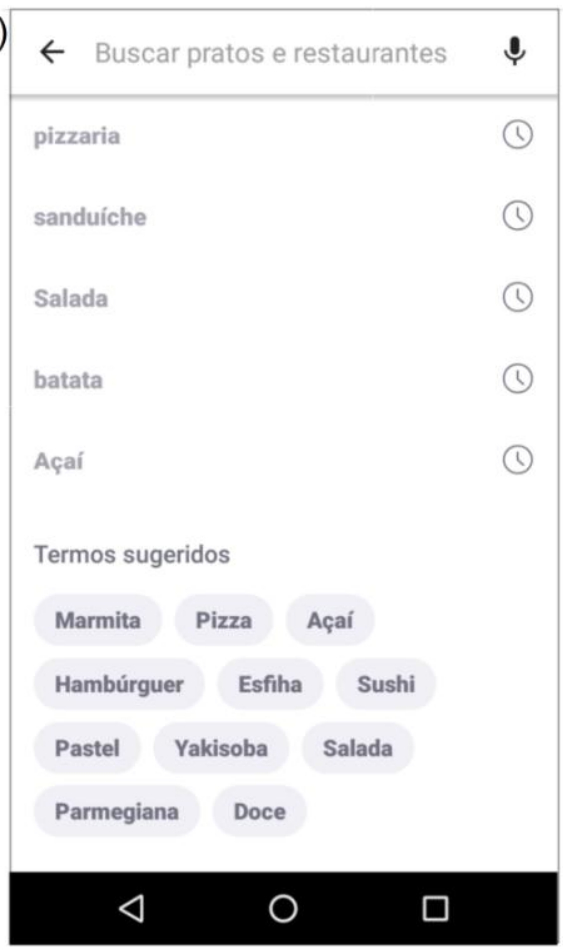

(2)

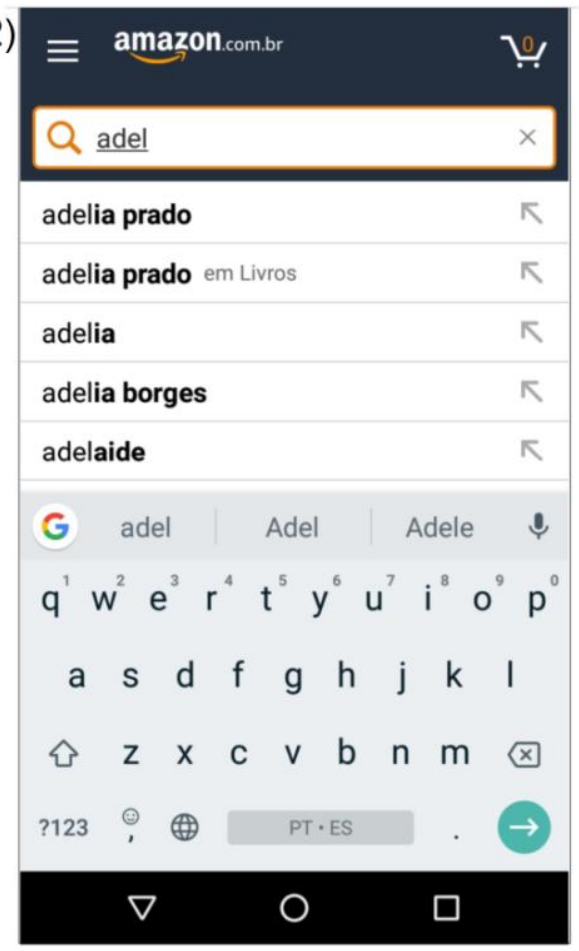

(4)

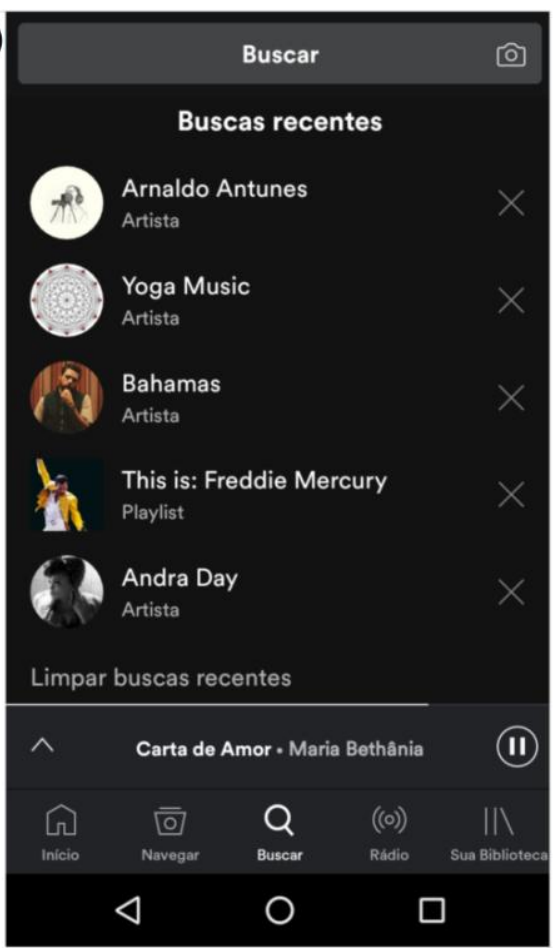

Fonte: Aplicativos Airbnb, Amazon, iFood e Spotify, adaptado pelos autores. Versões sistema operacional Android.

Legenda: (1) Airbnb; (2) Amazon; (3) iFood; (4) Spotify. 
A ferramenta de busca de informação no aplicativo Airbnb é exibida na parte superior da tela inicial. Uma vez selecionada a área do campo destinado à inserção do termo de pesquisa, a ferramenta é expandida e surge o histórico dos termos utilizados em buscas recentes e as opções de filtros responsáveis por restringir o conjunto de informações a ser recuperado. A partir de um dos filtros, "Próximo", nota-se a integração das funcionalidades do aplicativo com o recurso de localização espacial - GPS -, a presença de serviço de recomendação, já que, uma vez selecionado, tal filtro recuperará informações relativas a ofertas de serviços em locais próximos ao endereço do usuário no momento em que realiza a pesquisa.

A inserção de parte do termo de pesquisa é suficiente para que o sistema de recuperação de informação do aplicativo ofereça sugestões que correspondam aos caracteres até então inseridos, por meio da função "autocompletar". Definido um termo de pesquisa, uma série de opções de serviços é oferecida de forma aleatória, sendo que, em alguns casos, há o agrupamento de sugestões de serviços que se assemelham quanto ao conteúdo.

Além das opções recuperadas que são diretamente relacionadas ao termo pesquisado, o sistema de busca, por meio da atuação do serviço de recomendação, recupera, também, sugestões indiretas que têm potencial interesse para o usuário. Baseado nos filtros empregados na pesquisa e nas características da opção - de serviço ou de acomodação - visualizada, o aplicativo reúne, sob os rótulos "Experiências adicionais para explorar" e "Casas parecidas", opções semelhantes de serviços, que se aproximam das preferências dos usuários, já que a mesma é traçada a partir das atividades individuais no contexto do aplicativo.

Por sua vez, a ferramenta de busca do aplicativo Amazon, também exibida na parte superior da tela inicial, apresenta, junto ao campo de inserção de termos de pesquisa, uma funcionalidade por meio da qual o consumidor pode fotografar produtos ou código de barras nos quais possui interesse, a fim de que a pesquisa seja feita por meio de imagens. Além da utilização direta da câmera 
do dispositivo móvel, o usuário também pode utilizar arquivos de imagens armazenadas no dispositivo para efetuar a pesquisa.

A ferramenta de busca oferece sugestões, genéricas ou específicas, aos termos de consulta à medida que caracteres são inseridos no campo destinado à pesquisa. A diferenciação das sugestões permite que o usuário possa ter acesso direto a diferentes produtos relacionados ao termo pesquisado, bem como a produtos relacionados a departamentos específicos.

Após a seleção do item, junto às informações recuperadas sobre o mesmo - descrição, características do produto etc. -, o serviço de recomendação do aplicativo destaca outros produtos que possivelmente podem ser de interesse do usuário. Nas seções "Comprados juntos com frequência" (associa o item selecionado a outros itens semelhantes), "Clientes que compraram este item também compraram" e "Clientes que visualizaram isso também viram", (exibem outras opções de produtos que possuem características aproximadas) são consideradas tanto as preferências do usuário quanto as da comunidade de consumidores. Nesse caso, pode-se notar uma clara aplicação de algoritmos na filtragem por conteúdo, colaborativa e com a adoção de algoritmos híbridos. Por fim, destaca-se que, junto à ferramenta de busca, é registrado o histórico de pesquisas recentes feitas pelo usuário.

No aplicativo iFood, a ferramenta de busca não possui a função autocompletar. As sugestões de termos são exibidas de modo fixo e genérico. Por limitar-se a poucos termos pré-definidos, observa-se que o aplicativo limita a experiência de compra do usuário. Na tela de busca é armazenado o histórico de termos já pesquisados em outros momentos.

Por sua vez, a ferramenta de pesquisa do aplicativo Spotify não é destacada na tela inicial, a exemplo do que ocorre nos demais aplicativos analisados neste estudo. A busca é feita por meio do ícone "lupa", localizado na barra de navegação inferior do aplicativo.

Uma vez selecionado esse ícone, o usuário é direcionado à tela de pesquisa, cuja parte superior exibe o campo para inserção dos termos de busca; abaixo desse campo, fica registrado um histórico de buscas recentes. À medida 
que os caracteres do termo de busca são inseridos, o aplicativo recupera informações referentes a diversas categorias, como músicas, artistas, podcasts, álbuns, playlists e perfis, por exemplo. Além de conteúdo diretamente relacionado ao termo pesquisado, são exibidos conteúdos indiretamente relacionados, ampliando a revocação.

Ressalta-se que o mecanismo de busca do aplicativo está associado ao serviço de recomendação, pois os resultados das pesquisas são configurados de acordo com as preferências do usuário - algoritmo de filtragem de conteúdo -, identificadas por meio de atividades anteriores no aplicativo. Assim, por exemplo, se um usuário habitualmente acessa conteúdos relacionados a determinado gênero musical, as buscas feitas no aplicativo tenderão a exibir resultados relacionados a esse universo à medida que os caracteres que compõem o termo de busca são inseridos no campo destinado à pesquisa. Nesse sentido, o primeiro item recuperado é apresentado ao usuário como "Melhor resultado" e indica algum artista que mais se aproxima das preferências individuais do usuário. Essa funcionalidade implica a incorporação dinâmica dos usos recentes.

A ferramenta de busca do aplicativo Spotify ainda apresenta outra funcionalidade de recuperação de informação: no campo de busca, encontra-se o ícone "câmera fotográfica" que, quando acessado, permite que o usuário escaneie, no smartphone de terceiros, uma espécie de código de barras que dará acesso ao mesmo conteúdo em seu dispositivo. Nota-se que o aplicativo intervém nas interações face-a-face ao permitir o compartilhamento das músicas e playlists em tempo real.

Os aplicativos foram comparados (Quadro 2) quanto aos seus mecanismos de recuperação da informação, o que permitiu a realização de uma análise global dos processos de busca de informação.

Quadro 2 - Características/funcionalidades relativas à busca de informação no contexto dos aplicativos

\begin{tabular}{|c|c|c|c|c|}
\hline \multirow{2}{*}{ Funcionalidades } & \multicolumn{3}{|c|}{ Aplicativos } \\
\cline { 2 - 5 } & Airbnb & Amazon & iFood & Spotify \\
\hline Função autocompletar & & & & \\
\hline
\end{tabular}




\begin{tabular}{|c|l|l|l|l|}
\hline Pesquisa por câmera & & & & \\
\hline Pesquisa por imagem & & $\begin{array}{c}\text { Não se } \\
\text { aplica }\end{array}$ & & $\begin{array}{c}\text { Não se } \\
\text { aplica }\end{array}$ \\
\hline Pesquisa integrada a GPS & & & \\
\hline $\begin{array}{c}\text { Serviço de recomendação } \\
\text { associado à ferramenta de } \\
\text { busca de informação }\end{array}$ & & & & \\
\hline $\begin{array}{c}\text { Emprego de algoritmos de } \\
\text { filtragem de conteúdo } \\
\text { filtragem colaborativa }\end{array}$ & & & & \\
\hline \begin{tabular}{c} 
Histórico de pesquisa \\
\hline
\end{tabular} & & & & \\
\hline
\end{tabular}

Dentre os sistemas analisados, percebeu-se que a ferramenta de pesquisa do aplicativo iFood apresenta apenas um recurso - pesquisa integrada a GPS capaz de potencializar a recuperação de informação. Tal limitação pode interferir na dinamicidade do consumo, uma vez que a ausência de outros recursos, como serviço de recomendação associado à ferramenta de busca, pode limitar a opção dos usuários a um número reduzido de estabelecimentos.

Em contrapartida, a diversidade de recursos relacionados à recuperação de informação presente nos demais aplicativos analisados amplia as opções dos usuários em obter acesso às informações que não estão imediatamente visíveis na interface reduzida dos dispositivos móveis.

\subsection{Compartilhamento de informação}

O compartilhamento de informação no contexto dos aplicativos analisados - à exceção do aplicativo $i F o o d$, que não apresenta esse recurso - ocorre de forma semelhante: dentre as informações constantes nos anúncios de produtos comercializados por cada organização, ou o próprio produto, no caso da organização Spotify, encontra-se a opção de compartilhamento daquele conjunto de informações ao qual o usuário tem acesso.

Tal opção permite que o compartilhamento seja feito a partir de outros aplicativos, por meio dos quais é possível disponibilizar o conteúdo a terceiros. Nota-se que o acesso às opções de compartilhamento nos aplicativos Airbnb e 
Amazon está diretamente visível por meio de botões de navegação, enquanto no aplicativo Spotify o acesso às opções de compartilhamento de informação se dá por meio de um menu associado às faixas de áudio, conforme pode ser verificado na Figura 3.

Figura 3 - Compartilhamento de informação no contexto dos aplicativos Airbnb, Amazon e Spotify

(1)
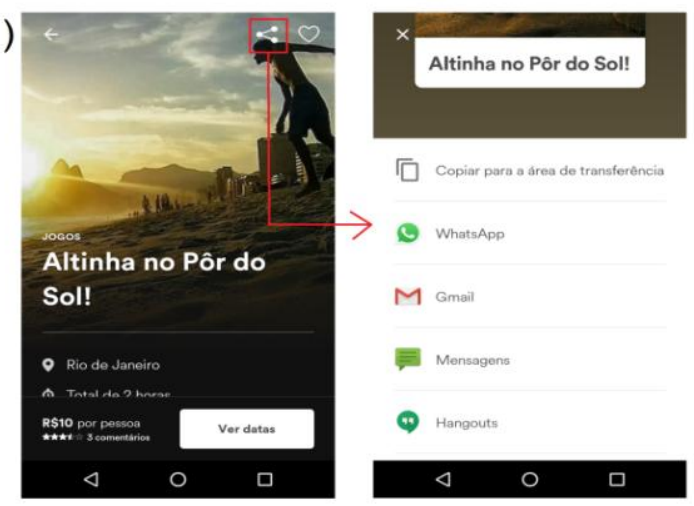

(2)
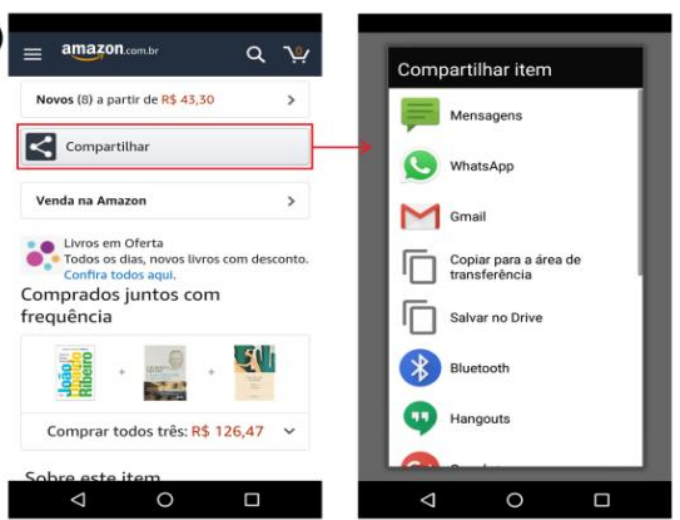

(3)
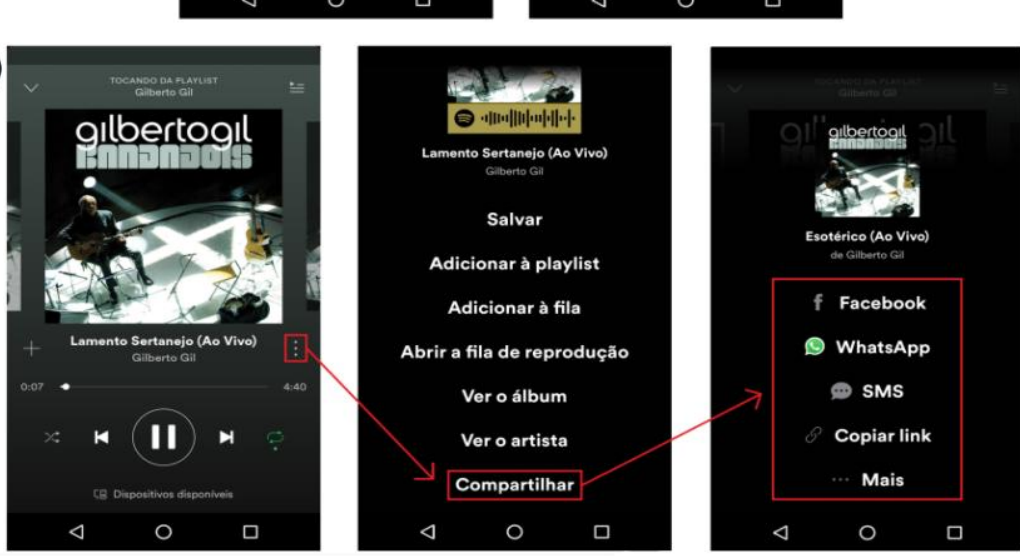

Fonte: Aplicativos Airbnb, Amazon e Spotify, adaptado pelos autores. Versões sistema operacional Android.

Legenda: (1) Airbnb; (2) Amazon; (3) Spotify. 
Acionada a opção de compartilhamento, são exibidos ao usuário todos os aplicativos instalados em seu dispositivo, por meio dos quais a difusão de informações pode ser feita. Enquanto alguns aplicativos - como aqueles de mensagem instantânea e de redes sociais, por exemplo - permitem o compartilhamento direto das informações em formato de links de acesso, outros permitem que as informações sejam transformadas em códigos passíveis de serem escaneados pela câmera fotográfica de dispositivos móveis, a fim de serem novamente convertidos nas informações originais.

O Quadro 3 explicita a comparação dos aplicativos em relação às funcionalidades voltadas ao processo de compartilhamento de informação.

Quadro 3 - Características/funcionalidades relativas ao compartilhamento de informação no contexto dos aplicativos

\begin{tabular}{|c|c|c|c|c|}
\hline \multirow{2}{*}{ Funcionalidade } & \multicolumn{3}{|c|}{ Aplicativos } \\
\cline { 2 - 5 } & Airbnb & Amazon & iFood & Spotify \\
\hline $\begin{array}{c}\text { Opções de } \\
\text { compartilhamento de } \\
\text { informação disponíveis }\end{array}$ & & & & \\
\hline $\begin{array}{c}\text { Links de } \\
\text { compartilhamento de } \\
\text { informações visíveis }\end{array}$ & & & & \\
\hline
\end{tabular}

Fonte: Elaborado pelos autores.

Apenas um dos aplicativos não apresentou funcionalidade relacionada ao compartilhamento de informação. No âmbito do comércio móvel, entende-se que a falta desse tipo de recurso compromete o fluxo informacional entre os membros da comunidade de usuários/consumidores, limitando o alcance às informações a esforços individuais ou a redes de contatos mais restritas.

\section{Considerações finais}

Embora haja variação dos modelos de negócio existentes no contexto do comércio móvel, percebeu-se que as atividades relacionadas ao consumo estão intrinsecamente associadas a fluxos e práticas informacionais. Tal associação pode ser identificada por meio das funcionalidades interativas presentes nos aplicativos e outros ambientes virtuais nos quais as organizações se fazem 
presentes. A partir de tais funcionalidades, afirma-se que as práticas informacionais vêm sofrendo modificações, que resultam na relação entre consumo informacional, interação mediada e consumo de bens e serviços.

Os ambientes de comércio móvel procuram incrementar a experiência de consumo dos usuários/consumidores por meio de funcionalidades que thes permitem, ainda que em determinadas condições, exercer um papel ativo do ponto de vista informacional. Nesse sentido, percebeu-se que a disponibilização de ambientes propícios à produção e o compartilhamento de conteúdo está ligada à intenção de intervir na percepção do usuário em relação ao seu controle sobre determinadas etapas do processo de consumo. Ao mesmo tempo, constatou-se que as informações disponibilizadas por consumidores servem como insumo para as organizações que atuam no comércio móvel, já que, por intermédio delas e dos relatos de experiência, é possível aperfeiçoar a prestação de serviços e a experiência de consumo, bem como identificar tendências de mercado. Ainda nesse contexto, ressalta-se, também, que as práticas de produção e compartilhamento de informação exigem que as organizações estejam atentas aos processos de comunicação organizacional que escapam ao seu controle - dimensão de “organização comunicada". Faz-se necessário que as organizações sejam capazes de dialogar com os consumidores - "organização comunicante" - a fim de que informações com conteúdo positivo sejam endossadas, enquanto aquelas carregadas de conteúdo negativo, capaz de atingir a imagem da organização, sejam atenuadas. Tal necessidade se justifica pelo fato de que, no comércio móvel, a ação do usuário é determinante.

Por fim, constatou-se que os mecanismos de busca de informação, adotados no contexto do comércio móvel, ultrapassam a característica de reatividade às demandas dos usuários. A presença ativa de algoritmos híbridos permite o acompanhamento do perfil dos usuários e de sua rede de interações e potencializa a oferta de novos serviços de valor agregado com o propósito de melhorar a experiência de consumo.

A atribuição de interatividade nas funcionalidades relacionadas às práticas comerciais revela a importância da informação para o desenvolvimento das estratégias de consumo no contexto do comércio móvel. Quanto mais 
coerentes e associados aos seus perfis forem os mecanismos de produção, busca e compartilhamento de informação, mais os usuários se sentirão confortáveis em realizar transações comerciais por meio das plataformas móveis. Nesse cenário, percebe-se que o grande desafio é conectar informacionalmente os indivíduos aos dinâmicos processos de consumo.

\section{REFERÊNCIAS}

AMAZON. Amazon.com.br. São Paulo: Amazon, c2017.

BALDISSERA, Rudimar. Comunicação organizacional na perspectiva da complexidade. Organicom: Revista Brasileira de Comunicação Organizacional e Relações Públicas, São Paulo, v. 6, n. 10/11, p. 115-120, 2009.

BARBOSA, Lívia; CAMPBELL, Colin. Cultura, consumo e identidade. Rio de Janeiro: FGV Editora, 2006.

BAUDRILLARD, Jean. A sociedade de consumo. Lisboa: Edições 70, 1991.

BLACKWELL, Roger; MINIARD, Paul; ENGEL, James. Comportamento do consumidor. São Paulo: Pioneira Thomson Learning, 2005.

BLOCH, Peter H.; SHERRELL, Daniel L.; RIDGWAY, Nancy M. Consumer search: an extended framework. Journal of Consumer Research, Chicago, v. 13, n. 1, p. 119-126, June 1986.

CANCLINI, Néstor García. Consumidores e cidadãos: conflitos multiculturais da globalização. 4. ed. Rio de Janeiro: Editora UFRJ, 1995.

CHAN, Felix T. S.; CHONG, Alain Yee-Loong. Analysis of the determinants of consumers' m-commerce usage activities. Online Information Review, Bradford, v. 37, n. 3, p. 443-461, 2013.

CONSTANTINIDES, Efthymios; FOUNTAIN, Stefan J. Web 2.0: conceptual foundations and marketing issues. Journal of Direct, Data and Digital

Marketing Practice, Basingstoke, v. 9, n. 3, p. 231-244, 2008.

DUAN, Wenjing; GU, Bin; WHINSTON, Andrew B. The dynamics of online word-of-mouth and products sales: an empirical investigation of the movie industry. Journal of Retailing, New York, v. 84, n. 2, p. 233-242, June 2008.

HENAO, Oscar; CÓRDOBA López, José Fernando. Comportamiento del consumidor, uma mirada sociológica. Entramado, Santiago de Cali, v. 3, n. 2, p. 18-29, jul./dic. 2007. 
HYRYNSALMI, Sami et al. Busting myths of electronic word of mouth: the relationship between customer ratings and the sales of mobile applications.

Journal of Theoretical and Applied Electronic Commerce Research, Talca, v. 10, n. 2, p. 1-18, May 2015.

ISLAM, Md. Rashedul; ISLAM, Md. Rofiqul; MAZUNDER, Tahidul Arafhim. Mobile application and its global impact. International Journal of Engineering \& Technology, Ras al-Khaimah, v. 10, n. 6, p. 72-78, Dec. 2010.

JESUS, Deise Lourenço de; CUNHA, Murilo Bastos da. Produtos e serviços da web 2.0 no setor de referência das bibliotecas. Perspectivas em Ciência da Informação, Belo Horizonte, v. 17, n. 1, p. 110-133, jan./mar. 2012.

LIPOVETSKY, Gilles. A felicidade paradoxal: ensaio sobre a sociedade do hiperconsumo. Lisboa: Edições 70, 2007.

MILLS, Leila A.; KNEZEK, Gerald; KHADDAGE, Ferial. Information seeking, information sharing, and going mobile: three bridges to informal learning. Computers in Human Behavior, Amsterdam, v. 32, p. 324-334, Mar. 2014.

MOON, Byeong-Joon. Consumer adoption of the internet as an information search and product purchase channel: some research hypotheses. International Journal Internet Marketing and Advertising, Cidade, v. 1, n. 1, p. 104-118, Jan. 2004.

NEUBERT, Patrícia da Silva; RODRIGUES, Rosângela Schwarz. Pesquisa bibliográfica e web 2.0: percepção de estudantes de pós-graduação em Ciência da Informação. Informação \& Sociedade: estudos, João Pessoa, v. 22, n. 3, p. 143-154, set./dez. 2012.

RIFKIN, Jeremy. A era do acesso: a transição de mercados convencionais para networks e o nascimento de uma nova economia. São Paulo: Makron Books, 2001.

SCHULTZ, Don E.; TANNENBAUM, Stanley I.; LAUTERBORN, Robert F. The new marketing paradigm: integrated marketing communications. Lincolnwood: NTC Business Books, 1993.

SOLOMON, Michel R. O comportamento do consumidor: comprando, possuindo e sendo. 9. ed. Porto Alegre: Bookman, 2011.

STERNE, Jim. Métricas em mídias sociais: como medir e otimizar os seus investimentos em marketing. São Paulo: Nobel, 2011.

TANG, Qian; GU, Bin; WHINSTON, Andrew B. Content contribution for revenue sharing and reputation in social media: a dynamic structural model. Journal of Management Information Systems, Abingdon, v. 29, n. 2, p. 41$75,2012$. 
TSAO, Wen-Yu. The fitness of product information: evidence from online recommendations. International Journal of Information Management, Amsterdam, v. 33, n. 1, p. 1-9, Feb. 2013.

ZHANG, Kem Z. K.; BENYOUCEF, Morad. Consumer behavior in social commerce: a literature review. Decision Support Systems, Connecticut, v. 86, p. 95-108, June 2016.

\title{
Production, Search and Information Sharing in the Context of mobile commerce
}

\begin{abstract}
It approaches the concept of consumption. It analyzes the development of the consumption society and the mass markets. It identifies characteristics of the consumer's behavior study. It approaches the changes in the e-commerce caused by the social media and applications for mobile devices. It displays the characteristics of social commerce and m-commerce. It describes the production, search and information sharing practices in the context of mcommerce. It evidences the informational practices from the functionalities present in the Airbnb, Amazon, iFood and Spotify applications. It verifies that, in the scope of m-commerce, the informational practices have suffered changes that result in the relations among informational consumption, sociability and goods and services consumption.
\end{abstract}

Keywords: Social commerce. Mobile commerce. Information practices. Mobile applications.

Recebido: $11 / 03 / 2018$

Aceito: 19/06/2018

${ }^{1}$ HOWARD, John A.; SHETH, Jagdish N. The theory of buyer behavior. New York: Wiley, 1969. Apud Henao; Córdoba López (2007).

${ }^{2}$ No original: "[...] sources of online information created, initiated, circulated, and used by consumers in intent on educating each other about products, brands, services [...]."

3 TIWARI, Rajnish; BUSE, Stephan. The mobile commerce prospects: a strategic analysis of opportunities in the banking sector.Hamburg: Hamburg University Press, 2007.

${ }^{4}$ KELLY, Robert F. The search component of the consumer decision process: a theoretic examination. In: MARKETING AND THE NEW SCIENCE OF PLANNING, Fall Conference, 1968, Chicago. Proceedings... Chicago: American Marketing Association, 1968. Apud Bloch, Sherrell e Ridgway (1986).

${ }^{5}$ No original: "[...] information seeking and processing activities wich one engages in to facilitate decision making regarding some goal object in the marketplace."

${ }^{6}$ No original: "[...] search activities that are independent of specific purchase needs or decisions." 